\title{
Researches of College Sports Technology Teaching Evaluation Methods
}

\author{
Kaiqiang Guo \\ Physical Education Institute of Jiangxi Normal \\ University \\ NanChang,JiangXi, China \\ 'guokaiqiang2008@yeah.net
}

\author{
Juan $\mathrm{Pu}$ \\ Physical Education Institute of Jiangxi Normal \\ University \\ NanChang,JiangXi,China
}

\begin{abstract}
Studies suggest that this method can not only improve professional sport technology teaching quality, but also enhance students' cognitive ability, athletic ability and promote the effectiveness of sports skills' formation. It also changes the traditional evaluation methods of oneness and solves the long-standing problems in $\mathrm{PE}$ teaching caused by the oneness of traditional subjective evaluation and experience evaluation.Objectively speaking, it is one of the important means to promote the development of higher school teaching reform and quality contraction and the direction of professional sport technology teaching and evaluation reform.
\end{abstract}

Keywords- network; computer software; sports technology; evaluation;

\section{INTRODUCTION}

A The evaluation of education informationization and networked education to now has become the indispensable auxiliary teaching method of modern higher school PE teaching. It can maximize the expansion and use of educational resources, improve the quality of education and played an irreplaceable role at some areas of sports training and teaching. Its auxiliary system can greatly improve the efficacy of teaching training and athletic performance.

B Higher school professional sport teaching is the professional technology practice process mainly based on body movement. Since different evaluation subject has different understanding at core level such as evaluation target, evaluation method and evaluation objects, the evaluation process and and the scientific nature of the appraisal conclusion, there is no unified standard now and many evaluation work and appraisal conclusions are questioned.

$\mathrm{C}$ The lack of understanding and sports evaluation implementation from the view of methodology and the divorce between PE assessment and research at scientific technology level are main problems that cause scarcity of theory to support PE evaluation. College sports professional technology teaching evaluation are usually based on experience evaluation and subjective evaluation, ignoring comprehensive evaluation method by the objective evaluation and qualitative and quantitative analysis, so the sports teaching professional sports technology evaluation method need to be reconsidered and innovation.

D Optimize the theory and practice of professional sports technology teaching evaluation process through designing, enriching and improving professional sports technology teaching evaluation process and the scene of teaching evaluation by targeted use of ideas and educational theory of the modern educational technology in the network environment.

\section{RESEARCH METHODS}

A Share evaluation information by using computer to establish professional sport technology teaching evaluation platform in networking environment.

B Computer images, graphics, video analysis, the use of Dartfish motion analysis software, super king and software for analysis of sports video

$\mathrm{C}$ Edit and make videos in line with professional teaching technology characters to evaluate and analyze by using Windows Movie Make.

$\mathrm{D}$ The literature material research, review the relevant six articles.

\section{RESEARCH CONCLUSION AND ANALYSIS}

A The basic theory concept of higher school professional sport technology teaching evaluation in networking environment: professional sport technology teaching and evaluation research in networking environment means the use of modern educational technology, computer graphics, graphics technology, and the relevant electronic communication device software etc. on the basis of the information technology involved through in sports teaching practice to assist to improve the scientific nature and effectiveness of the professional sports technology teaching evaluation effectiveness.

B The use of educational technology in the networking environment can give full play to the excellent teaching staff and resources. Multimedia, including text, images, sound, animation and other computer network communication technology transfer, a variety of teaching can enrich teaching content, stimulate students' environment, make it easier for students more quickly and vividly grasp the learned knowledge and improve the teaching quality to create well learning effects. Networked learning environment will make it easier to access information. Students will be promoted to learn by need and gradually form a student-centered initiative learning mode.

C Higher professional sports technology teaching evaluation aims to make students master professional 
technical motor skills reasonablely, reform teaching method, improve teachers'research ability and teach students to learn, improve cognitive ability and students'ability to solve and analyze problems by application of computer technology and multimedia technology to assist teaching and evaluation in the networking environment.

D In the networking envirnment, PE teacher leads the change of domiant roles. In the traditional teaching mode, the teacher is always in a dominant position. The teaching effectiveness and quality are single and unbalanced. Establish teaching and evaluation platform in the networking environment and scientifically analyze technical image of different stages to solve problems encountered by students in their learning process and improve their initiative learning ability. It can give full play to teachers' domiant effectiveness and students' domiant roles and plays a great role in formation of PE sport skill and promoting effectiveness of teaching training.

E Principles of sports teaching evaluation in the networking environment,

(1) Subjectivity: networks in the professional sport technology teaching hit and improve the traditional teaching mode and reflect the student-centered learning mode. It is more conducive to students' cultivation of "learning to learn" ability and fully mobilize the enthusiasm of the students so that students take the initiative to discover knowledge, to explore and gain knowledge.

(2) Treat differently: that is, different students have different evaluation criteria, even if for the evaluation of the same content for different students. Its value judgments should be colorful and lively.

(3) Relevance: The evaluation must have a clear focus.Every evaluation must have a specific purpose, not just for the sake of evaluation. The specific purpose of the evaluation determines evaluation criteria and the specific approach of the evaluation.

(4) Comprehensiveness:every project of the evaluation criteria should not be too prominent.Do not judge without full collection of relevent information in the evaluation process. Implement the principle of comprehensiveness in professional sports teaching evaluation. We must not only seize the comprehensiveness of the evaluation criteria but also the comprehensiveness of information collection in evaluation process .

F Physical Education Teaching and Evaluation Methods in the network environment: over the years, higher school professional sports technology teachers' scientific research level in our country is relatively low and the evaluation of teaching effectiveness has been subjective and experiencebased. The teachers guide the technical action course of students by virtue of the visual and subjective experience, so students can only grasp technology behavioral essentials by passive repetitive practice. Such a subjective one-sided teaching evaluation methods will finally be eliminated.

(1) Set the platform and application environment of sports teaching and evaluation intje networking environment by the use of network technology. Use the software such as Dartfish, Windows Movie Make, Super King etc. to analyze and decompose screenshots of video. Use graphic image analysis techniques to study techniques and action. Observe the route at the start of the action process and compare with the demonstration in Figure in order to identify the key factors affecting the technical movements and enable students to be targeted for a deeper learning.

(2) Application environment: quality courses network teaching platform, qq groups of students curriculum and classes, forums, oneline SMS platform of school attendance. This pluralism of interactive platform can contribute to the teaching effectiveness of Double subject teaching mode.

(3) Specific operating procedures and characteristics, see Figure 1:

a) Teachers make multimedia courseware to assist teaching, treat professional sports technical curriculum as content and technology of elite athletes as materials to produce professional multimedia courseware to facilitate students' understanding and perception of the technology and to promote learning.

b) Record the students' technical action video regularly in line with the teaching programs and learning progress. In each semester, record the special skill of student one by one

by the use of digital video recording, a variety of film equipment such as DV shooting.

c) Use computer software and modern educational technology for the diagnosis and evaluation of the athletic skills of the students, put video clips into the computer, use the video editing functions of Super King, key technical error marked or crossed by Dartfish software. Made ppt presentation uploaded to the quality courses, qq group of classes and network platform for technical diagnosis, or parallel action gallery of elite athletes with it. Found that students' technical problems, and to facilitate student selfevaluation, student-student evaluation, and teacher-student evaluation, and test the teaching effectiveness.

d) Guide students to self-diagnosis and use video playback software for students to demonstrate his technical action. At the process of practice learning, the vast majority of students can not see their actions; just relying on proprioception is not enough to determine the accuracy and aesthetics of the technical action. Student forms the initial self-diagnostic mode through the video and their action experience degree.

Figure 1:

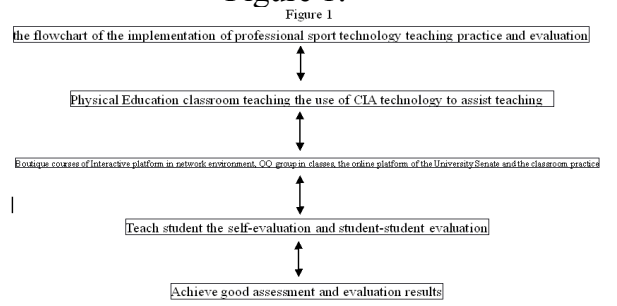


G For example: In the practice teaching and learning of spike, the tackle of the problem existing at the run-up jump details of spike.

The strength and harmony of arm waving of Spiking technique at take-off is a direct impact on take-off height and smash effect. Take run-up arm waving of Lang Ping, one of the world's three major spike hand as example, use the Dartfish movement analysis software to analyze Lang Ping's arm waving of run-up jump video. Study characteristics of swing of Lang Ping's run-up and jumping, shown in Figure 2

Swing action, use the method of swing as stroke arc. Through the processing and analysis of computer graphics and image, it can be found that her characteristics of the swing at run-up jump as following: A coherent and coordinated action B Arms draw an arc by a big margin, two arms swing after the body to the level position. Adjust the arm speed and rhythm according to the passing ball 2. C the movement trajectory of the body gravity significantly move smoothly from the level to the height, then slightly down with the take-off technical process

See Figure 2

Pedal angle of the jump knees change from 150.30 degree to 98.50 degree. Figure 3 shows, demonstrate the strong pedal strength. The whole trajectory of body gravity smoothly changes until to accelerating process. The changing curve of Lang Ping's swing of run-up jump. Its direct role is to speed up the conversion from the horizontal speed to vertical speed. The support angle of knees changes from large to small which facilitate thigh muscles to stretch and contract. The three characteristics above are three main factors decide Lang Ping's spike advantages

Figure 2 action diagram of Lang Ping's swing at run-up and take-off

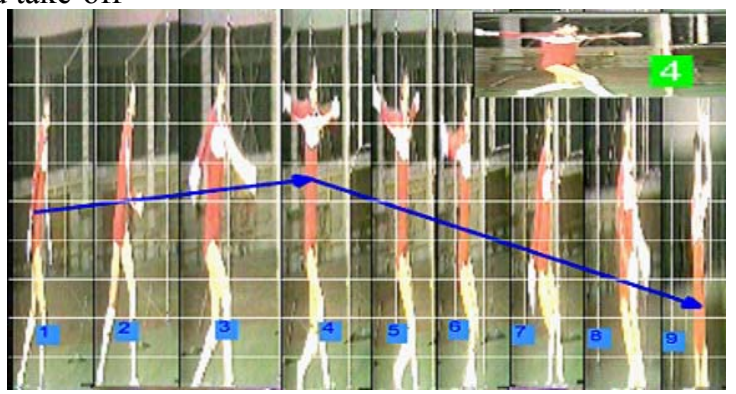

The above analysis is valuable for targeted training details of a variety of swing at run-up jump in real spike teaching.
Figure 3.

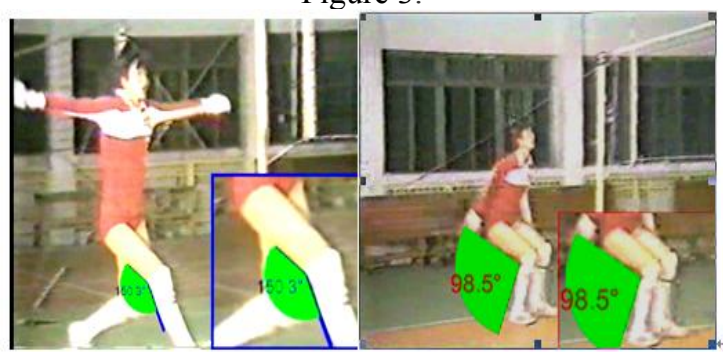

$\mathrm{H}$ Use Windows Movie Make to introduce digital video technology for editing, evaluate and analyze professional sports technology teaching video. The use of technical action Dartfish motion analysis software, images, graphics technology structural analysis, set up video demo contrast in the networking environment for professional sport technology evaluation. The main purpose aims to compare motion characteristics of elite athletes with students' technology and find out gaps. Figure 4, Figure 5 shows. Achieve the process and analysis of the information in the teaching and learning process. The use of CAI technology to record digital video of student's technical motion and import boutique school courses online teaching platform to make technical analysis and diagnosis and evaluation.

The main reflection:

(1)Enlarge students' vision of learning knowledge stimulate students' interest in study and learning motivation, arouse the students to take part in the teaching activities of the interest.

(2) Improve student's perceptive ability of professional sports technical motion, analytical ability and operation ability of technical formation.

(3) But also for students to study the creation of favorable external conditions, in order to actively guide students to complete the scheduled teaching plans and objectives. Ultimately achieve the purpose to improve students' skill levels. Table 1 show
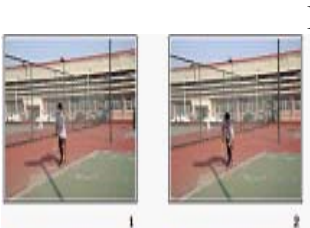

Figure 4
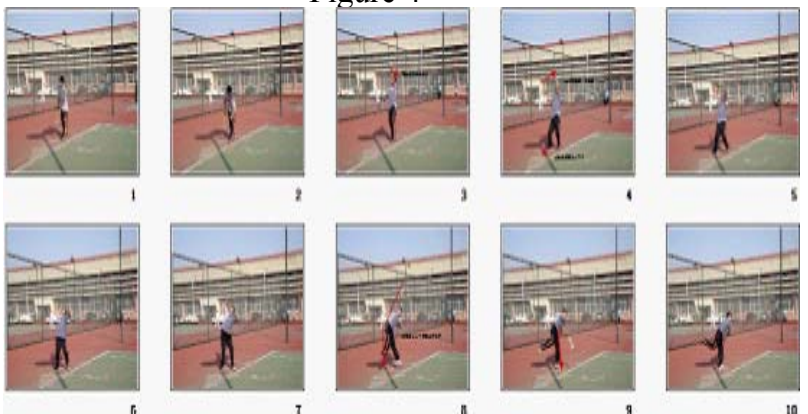
Table 1; evaluation form of students's serve images and graphical presentation Serial

\begin{tabular}{|c|c|c|c|}
\hline Nurnber & errivation cortertit & tessitts of evaluation digagnosis & ingroverenents \\
\hline 1 & 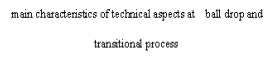 & 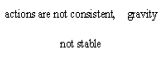 & Stengenten drop trising \\
\hline 2 & 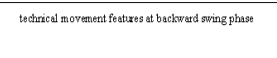 & den't stetctin & 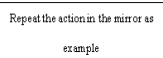 \\
\hline 3: & 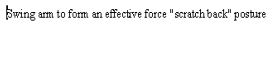 & Donofortin & $\begin{array}{l}\text { Reep an the side and andack of tre } \\
\text { demononstration action }\end{array}$ \\
\hline 4 & 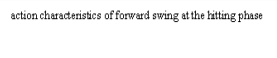 & stereghth scetetered & $\begin{array}{l}\text { To strenghthenthe powet of the } \\
\text { upper and lowes linbs bytratining }\end{array}$ \\
\hline 3 & Approfriate batting cirick & Hit a slow point & $\begin{array}{l}\text { hit the highest poirt of the tipical } \\
\text { object }\end{array}$ \\
\hline 6 & do arn rotaion viit uppers limb $b$ & Wot thinus & $\begin{array}{l}\text { tain the cant to pity in rottaion and } \\
\text { cotth the ball }\end{array}$ \\
\hline
\end{tabular}
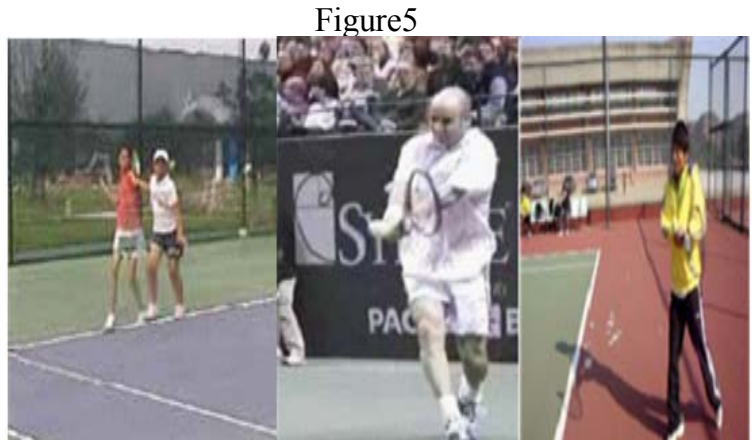

Figure 5 is the diagnosis of contrast analysis and evaluation of the overlap of students tennis forehand 's hitting technology and the hit picture with double backhand. The result is that the technical action of student hitting with forehand is similar with that of elite athletes.

There are differences between backhand dualhanded hitting students, mainly: Movement and racket position is not in place. Hitting point is not accurate. Forearm position did not hit the ball straight.

Through the implementation of the teaching evaluation methods in the network environment can not only improve the quality of professional sport technical curriculum,but also enhance students' cognitive ability and athletic ability, and promote the effectiveness of motor skills. Also changed the traditional unity of evaluation methods. It changes the long-standing traditional subjective and expirical evaluation in physical education, thus achieve to change from the unique teacher evaluation to teacher-student evaluation, student-student evaluation, and finally develop to explore evaluation and research evaluation.

\section{CONCLUSION}

In short, Min the network era, the mode of rigid and traditional professional higher school sport technical teaching evaluation will be hitted and changed. Optimize the theoretical and practical process of professional sport technology teaching and evaluation by full use of information technology, design, enrich and improve of professional sport technology teaching process and teaching evaluation scene. Expand the vision of student to learn new knowledge, to stimulate students' interest and motivation to learn, mobilize student to take part in learning activities and improve student's cognitive abilities, analytical skills and ability of operation of higher school professional sport technical motor skills. Objectively speaking, it is one of the important means to promote The teaching reform of higher quality engineering construction and the reform guide of professional sport technology teaching and evaluation.

Jiangxi Normal University Youth Fund Project

\section{REFERENCES:}

[1]. Kaiqiang Guo,CAI Teaching Design and Development for referee scoring of table tennis-----a case of Tennis Excellent Courses of Jiangxi Normal University [C] The 2nd International Conference on Multimedia Technology (ICMT2011)IEEE Catalog Number: CFP1153K-PRT

ISBN: 978-1-61284-772-6。2993-2997。

[2].Kaiqiang Guo, The Characteristic Analysis of Lang ping's Front Spike Skill of Volleyball. The World Congress on Engineering and Technology [C] (CET 2011) IEEE Catalog Number; CFP1148N-PRT ISBN:978-161284-362-9。833-836.

[3].PU Juan, GUO Kaiqiang, Teaching and Evaluation of Tennis Serving Technique under Network Environment . [C] PROCEEDINGS OF THE 22ST PAN-ASIAN CONGRESS OF SPORTS AND PHYSICAL EDUCATION. World Academic Union, ISBN978-1-84626-101-5.

[4].http://www.dartfish.com/en/support/index.htm

[5].Zhang Yongdong, sports video analysis technology and its applications, [EB] gold medal coach network

[]6.Tang Li Xu, Cai Zhonglin, the sports Evaluation Research Review [J] Shanghai Institute of Physical Education, 2011.03. 28-30. 